\title{
Congenital Chylothorax: Management and Long-term Outcome A Case Report and Literature Review \\ Salma Ben Ameur*
}

Department of pediatrics Hedi Chaker Hospital, El Ainstreet, Tunisia

\begin{abstract}
Congenital chylothorax is the most common cause of pleural effusion in the neonatal period. We describe a 9 days old new born admitted for respiratory distress. The chest X-rays showed a white right lung with a left mediastinal shift. A pleural aspiration assessed the diagnosis of chylothorax. Lympho-scintigraphy detected rapid drainage of lymph into the right side of the chest. A conservative treatment was initiated with pleural aspirations and total parenteral nutrition followed by enteral feeding using semi elemental formula. This treatment was effective and the child was discharged from the hospital at the age of 40 days. A 6 years follow-up, revealed no recurrence of the chylothorax.
\end{abstract}

Keywords: Congenital chylothorax; Pleural effusion; Respiratory distress

\section{Introduction}

Congenital Chylothorax (CT), defined, as the accumulation of lymphatic fluid in the pleural cavity, is a rare neonatal disorder. Nevertheless, congenital chylothorax represents the most common cause of pleural effusion in fetuses and newborn [1]. Chylothorax may lead to high morbidity and may even threaten survival, because of respiratory distress and large losses of lymphocytes, proteins, and immunoglobulins. The treatment options of congenital chylothorax are still controversial [1,2]. Here, we report a new case of idiopathic congenital chylothrax and discuss the different therapeutic approaches and neonatal and the long term outcome.

\section{Case Report}

M.., a female new born, was admitted at the age of 9 days for respiratory distress. She was born by normal vaginal delivery at full term pregnancy, which was poorly monitored. The birth weight was $3400 \mathrm{~g}$, and the Apgar scores were 7 at 1 minute and 8 at 5 minute. The parents were non consanguineous and there were no hereditary disorders in family history.

On examination, the temperature was $37.5^{\circ} \mathrm{C}$, the pulse 150 beats per minute, the respiratory rate 80 breaths per minute, and the oxygen saturation $88 \%$ in room air an removed to $95 \%$ after supplemental oxygen. The infant appeared tachypneic and groaned. Auscultation revealed decreased breath sounds on the right. There was no dysmorphic features and the remainder of physical examination were unremarkable.

The chest X-rays showed a white right lung with a left mediastinal shift (Figure 1). The chest scan revealed an important right pleural

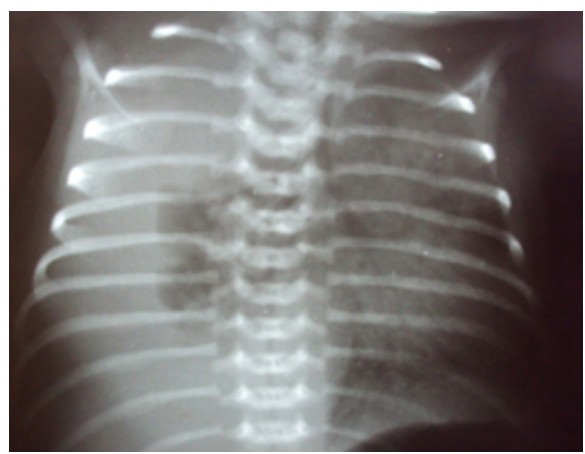

Figure 1: Chest X-rays showed a white right lung with a left mediastinal shift.

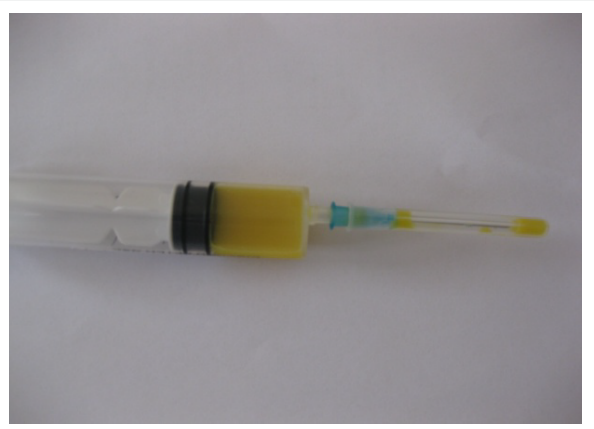

Figure 2: Milky pleural fluid.

effusion. Thoracocentesis yielded milky fluid suggestive of chylothorax. (Figure 2).

Pleural fluid analysis showed 1200 white blood cells $/ \mathrm{mm}^{3}$ with $80 \%$ lymphocytes, $73 \mathrm{~g} / \mathrm{l}$ of protein, $3.9 \mathrm{mmol} / \mathrm{l}$ of cholesterol and 20.55 $\mathrm{mmol} / \mathrm{l}$ of triglycerides. The culture was negative. Blood count showed a hemoglobin of $15 \mathrm{~g} / \mathrm{dl}$, white blood cell count of $20000 / \mathrm{mm}^{3}$ with $67 \%$ neutrophils, $30 \%$ lymphocytes. Other laboratory investigations revealed normal blood urea nitrogen, creatinine, electrolytes, triglyceride (1.12 $\mathrm{mmol} / \mathrm{l})$ and cholesterol $(3.9 \mathrm{mmol} / \mathrm{l})$.

Cardiac ultrasound was normal. Radionuclide lymphoscintigraphy

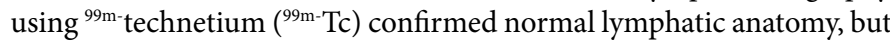
also detected rapid drainage of lymph into the right side of the chest.

The infant was started on total parenteral nutrition. Because of increasing tachypnoea, thoracocentesis was repeated on the 10 th day after admission and extracted a volume of $60 \mathrm{ml}$. Improvement of respiratory distress was so noted. Follow-up chest X-ray revealed decrease in the pleural effusion. Enteral feeding, using a semi elemental

*Corresponding author:Salma BenAmeur, Department of pediatrics Hedi Chaker Hospital, El Ain Street Km 0.5 ; 3029 Sfax Tunisia, Tel: 0021698429490; Fax: 0021674249157; E-mail: benameursalma@gmail.com

Received November 06, 2015; Accepted December 11, 2015; Published December 18 2015

Citation: Ameur SB (2015) Congenital Chylothorax: Management and Longterm Outcome A Case Report and Literature Review. J Clin Case Rep 5: 668. doi:10.4172/2165-7920.1000668

Copyright: (c) 2015 Ameur SB. This is an open-access article distributed under the terms of the Creative Commons Attribution License, which permits unrestricted use, distribution, and reproduction in any medium, provided the original author and source are credited. 
formula (peptujinior ${ }^{\circledR}$ ) was then initiated after 15 days. Control's scintigraphy showed normal opacification of the thoracic duct.

The child was discharged from the hospital at the age of 40 days. Her growth and development were appropriate for her age on subsequent follow-up. The chromosome analysis revealed normal female karyotype. A 6 years follow-up, revealed no recurrence of the chylothorax with a normal growth and psychomotor development.

\section{Discussion}

Chylothorax is a rare disease (1-2\% of pleural effusions), with a prevalence between $1 / 8600$ and $1 / 15,000$ births [3]. Congenital chylothorax typically presents at birth, or within the first week of life. The presentation is one of respiratory distress and the diagnosis is typically confirmed by pleural aspiration of a milky fluid with triglyceride levels $>1.1 \mathrm{mmol} / \mathrm{L}$ and total cell counts $>1,000$ cells per $\mathrm{ml}$ with $80 \%$ lymphocytes [1-3].

Chylothorax may be either acquired or congenital. Acquired chylothorax is usually due to trauma to the thoracic duct during cardiac or thoracic surgery. Congenital chylothorax is associated with abnormalities of the lymphatic system such as lymphangiomatosis and lymphangiectasia, congenital heart disease, mediastinal malignancies and chromosomal abnormalities (trisomy 21, Turners and Noonan syndromes). Many cases of chylothorax have no clear etiology and are considered as idiopathic congenital chylothorax like the newborn presented here. The mechanism is thought to be either traumatic, with rupture of the thoracic duct by hyperextension of the spinal column or secondary to increased systemic venous pressure during birth, especially in complicated deliveries [1].

In adults, lymphography has been used to define the anatomy, but is not practical in children due to difficulty cannulating lymphatics [1]. For this reason, we used radionuclide lymphoscintigraphy instead. This showed leakage of chyle above the diaphragm on the right side.

Patients with chylothorax may be treated by conservative means or surgery $[1,2]$. Conservative treatment includes pleural drainage or repeated thoracocentesis and dietary modifications to reduce the flow of chyle through the thoracic duct while waiting for spontaneous healing [1].

This is usually managed by cessation of oral feeds with total parenteral nutrition, followed by re-establishment of feeds using Medium-Chain-Triglycerides (MCT) based milk formulas which are expensive and not easily available in Tunisia. In the present case, we have successfully used a semi elemental formula with $49 \%$ MCT fat.
Some case reports have been described regarding the use of octreotide as an alternative treatment to infants not responding to conservative management. Octreotide has a wide range of inhibitory effects on gastrointestinal and endocrine function. Its mechanism of action in treating chylothorax is unclear, but a possibility is reduction of splanchnic vascular tone, eventually leading to a decreased flow of chyle through the thoracic duct $[1,2,4]$.

Surgery should be considered when medical management fails with either excessively prolonged ( $>3$ to 4 weeks) drainage or $>10 \mathrm{ml} / \mathrm{kg} /$ day or $>100 \mathrm{ml} /$ year of age. Some approaches are reported: thoracic duct ligation, pleurodesis and pleura-peritoneal shunts are the most utilized [1,2].

In a retrospective analysis of 23 newborns with chylothorax, 17 were treated conservatively, and 6 with massive chylothorax were treated surgically. Surgical treatment varied, including en masse thoracic duct ligation, mechanical pleurodesis, and application of fibrin glue [5]. The long-term prognosis seems to be favourable if not associated with genetic disorders like the present case [6-8].

\section{Conclusion}

Chylothorax is a rare cause of respiratory distress in newborns. Its diagnosis is based on clinical, radiological, and pleural fluid biochemical findings. Conservative therapy is successful in about $80 \%$ of reported cases and should so be tried at first [1]. '

\section{References}

1. Soto-Martinez M, Massie J (2009) Chylothorax: diagnosis and management in children. Paediatr Respir Rev 10: 199-207.

2. Mitanchez D, Walter-Nicolet E, Salomon R, Bavoux F, Hubert P (2006) Congenital chylothorax: what is the best strategy? Arch Dis Child Fetal Neonatal Ed 91: F153-154.

3. Epaud R, Dubern B, Larroquet M, Tamalet A, Guillemot N, et al. (2008) Therapeutic strategies for idiopathic chylothorax. J Pediatr Surg 43: 461-465.

4. Chemaou A, Ayachi M, Ailal F, Najib J (2012) [Idiopathic chylothorax in an infant: management and progression]. Arch Pediatr 19: 711-713.

5. Shah D, Sinn JK (2012) Octreotide as therapeutic option for congenital idiopathic chylothorax: a case series. Acta Paediatr 101: e151-155.

6. Bialkowski A, Poets CF, Franz AR (2015) Erhebungseinheit für seltene pädiatrische Erkrankungen in Deutschland Study Group. Congenital chylothorax: a prospective nationwide epidemiological study in Germany. Arch Dis Child Fetal Neonatal Ed 100: 169-72.

7. Downie L, Sasi A, Malhotra A (2014) Congenital chylothorax: associations and neonatal outcomes. J Paediatr Child Health 50: 234-238.

8. Ergaz Z, Bar-Oz B, Yatsiv I, Arad I (2009) Congenital chylothorax: clinical course and prognostic significance. Pediatr Pulmonol 44: 806-811. 